\title{
PERSONAL PRACTICE
}

\section{How to manage warts}

Julian Verbov

Warts are caused by DNA-containing human papillomavirus (HPV). These viruses are found in the upper epidermis and cause squamous epithelial cell proliferation. At least 70 types of HPV exist, ${ }^{1}$ but some types tend to be more common in certain body areas. Common warts (on hands) are due mainly to HPV2 but also to types 1 and 4 . Plantar warts also involve HPV 1,2 , or 4 with mosaic warts commonly caused by HPV2. Flat warts are mainly due to HPV types 3 and 10 . The incubation period is probably many months.

\section{Incidence}

Viral warts are extremely common in children, particularly in those over 3 years old. Incidence peaks between the ages of 12 and 16 years.

\section{Diagnosis}

Warts over the fingers (fig 1) are the most common presentation but plantar warts (verrucae vulgaris) and knee warts are also commonplace. It should be noted that gentle paring of plantar warts reveals small capillaries which will be absent if pared skin is simply hard skin (callus). When considering best management, it should be remembered that up to $30 \%$ of warts disappear spontaneously within six months and most disappear spontaneously within three years; this really does happen. It seems that the soil (that is, the skin) ceases to allow virus replication and the wart disappears. I should mention here that warts are often rough to touch unlike another common self limiting virus infection-molluscum contagiosum - where individual mollusca are smooth and hemispherical and often show central umbilication.

Over the hands warts may be florid, but over the soles, hard skin (callus) overlying warts is often prominent. Trauma to warts, particularly plane warts over the hands, may produce spread in the line of the trauma-an example of the Köbner phenomenon (fig 2). Warts around fingernails are usually associated with nail biting or picking. Plane (flat) warts and warts in a mosaic (grouped) pattern over soles (fig 3) tend to be more resistant to treatment.

Flat warts are seen over the face and backs of hands at times. Filiform (thread-like) and digitate (finger-like) warts (fig 4) are also not uncommon over the face. Although genital warts (fig 5) in children are usually not the result of sexual abuse, this must always be con- sidered, and a thorough history taken and relevant points noted on examination. Genital warts usually occur as a result of transmission of virus from somewhere else over the body or from contact with a person carrying the virusfor example, from a mother with warts who bathes the child and transmits the virus from herself to the child. It is my impression that genital warts often present at an earlier age than extragenital ones.

Immunosuppressed individuals are more susceptible to viral warts than others. Children with atopic dermatitis may have more extensive and persistent warts associated both with their decreased immune resistance to the virus and with use of the more potent topical corticosteroids for eczema. However, it is interesting that a recent paper from Australia reports no difference in the overall frequency of warts between those who had eczema and those who did not. ${ }^{2}$

\section{Management}

As we approach the year 2000 there is still no specific anti-wart treatment and we generally

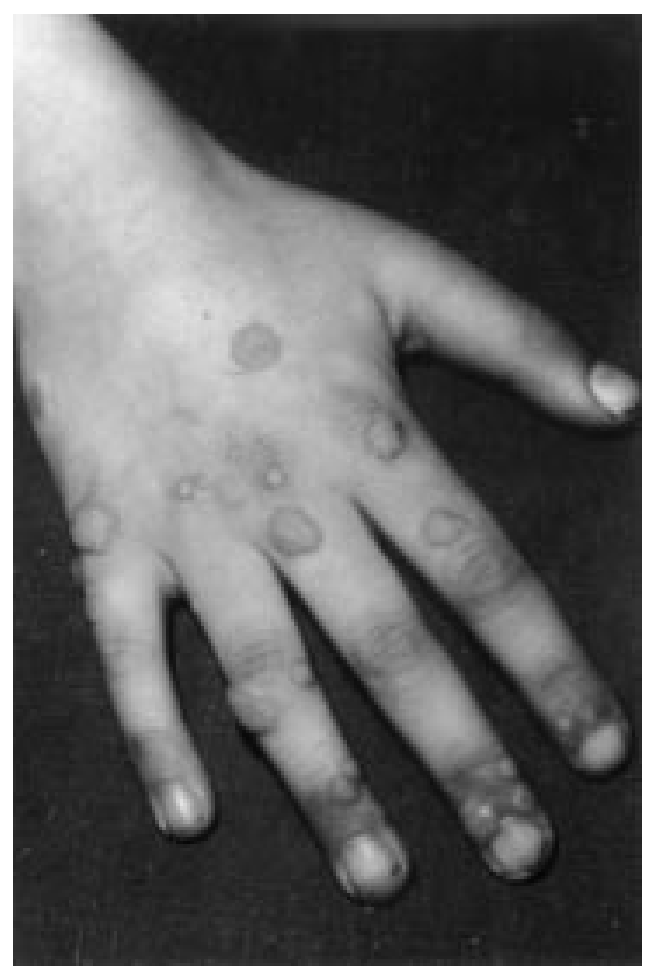

Figure 1 Common hand warts.
Consultant Paediatric Dermatologist, Alder Hospital, Liverpoo L12 2AP, UK J Verbov

Correspondence to: Professor Verbov 


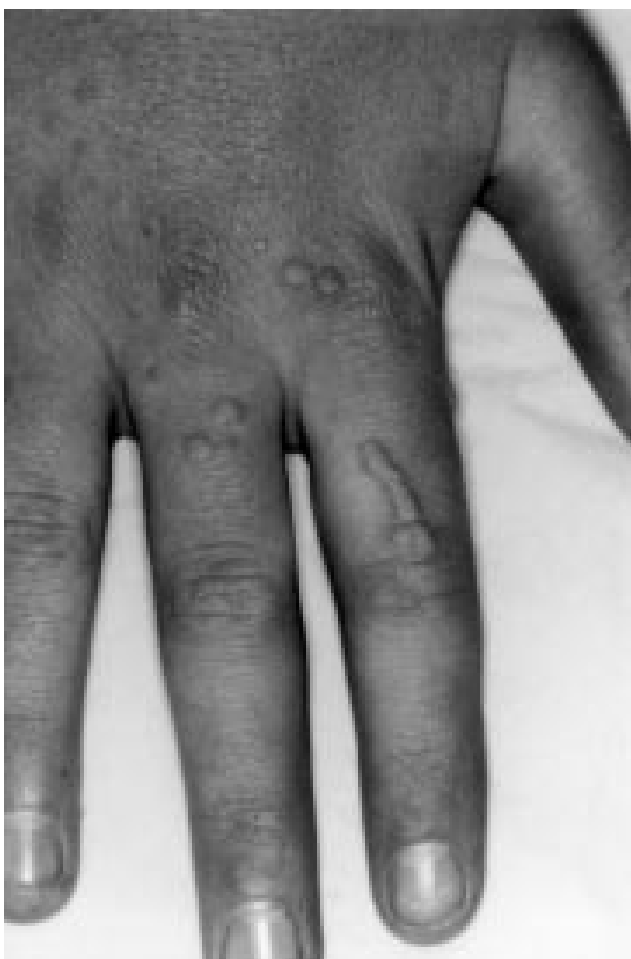

Figure 2 Finger warts showing Köbner phenomenon.

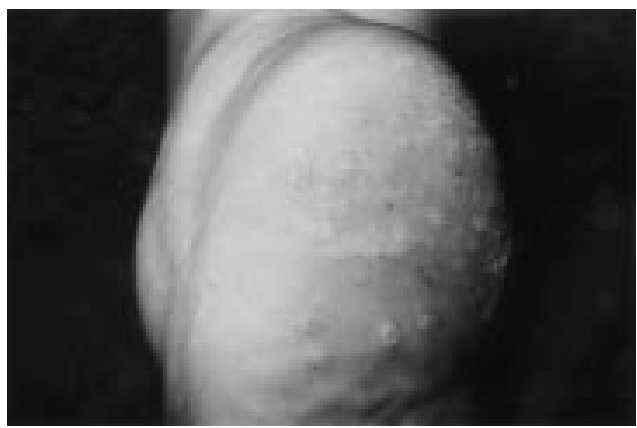

Figure 3 Mosaic and ordinary plantar warts over heel.

rely on destructive methods of treatment. However, treatment must not be more unpleasant than the condition. ${ }^{3}$ Because warts are self limiting, reassurance should be the mainstay of management and time is well spent explaining this to parents.

Paring plantar warts can reduce discomfort and encourage penetration of topical applications. Inexpensive scrapers are readily available to remove the hard skin from soles and are more useful than pumice stone. Any pain in plantar warts is due to overlying hard skin, secondary infection, or inflammation (often of normal surrounding skin) by too strong a local application. Contact dermatitis due to a local application or adhesive plaster occurs occasionally.

Occluding warts with a verruca sock or waterproof plaster when swimming helps prevents transmission of the virus, and such socks may also prevent warts occurring over the soles.

For plantar and common warts useful preparations are glutaraldehyde $(10 \%)$ solution; salicylic acid collodion BP; salicylic acid $(16.7 \%) /$ lactic acid $(16.7 \%)$ paint or solution; and salicylic acid solution (26\%). For all preparations, application to healthy skin should be avoided.

For larger warts over hands, knees, and occasionally soles, cryotherapy with liquid nitrogen $\left(-195^{\circ} \mathrm{C}\right)$ can be used, applying the liquid for about 10 seconds with a cotton wool bud on the end of an orange stick or by spray to each individual lesion. Topical anaesthetic cream (EMLA) may reduce the pain experienced during cryotherapy at some sites, ${ }^{4}$ but I usually find it unnecessary for routine use.

Filiform warts over nose (or in the nasal vestibule), lips, or cheeks can be treated with liquid nitrogen for a few seconds only. Carbon dioxide snow requiring longer application than liquid nitrogen is older alternative cryotherapy that is less effective than nitrogen. Liquid nitrogen must be applied with care: hazards include nail dystrophy, tendon rupture, and damage to joints or nerves. ${ }^{5}$

For perianal or vulval warts, salicylic acid (3-5\%) in an emulsifying ointment at night, or cryotherapy with liquid nitrogen for 2-3 seconds only every 3-4 weeks are useful. Podophyllin $(5-15 \%)$ in compound benzoin tincture can be applied by an experienced nurse or general practitioner twice weekly for a few applications; initial application should be with 5\% concentration: the treated area must be washed with soap and water 4-6 hours later. Occasionally, intractable extensive genital warts may require surgical removal. Intraoral lip warts may occasionally require curettage under local anaesthesia but liquid nitrogen is usually effective.

Tretinoin cream $(0.025 \%)$, a synthetic retinoid, has been used to treat hand and facial plane warts and may be considered in older

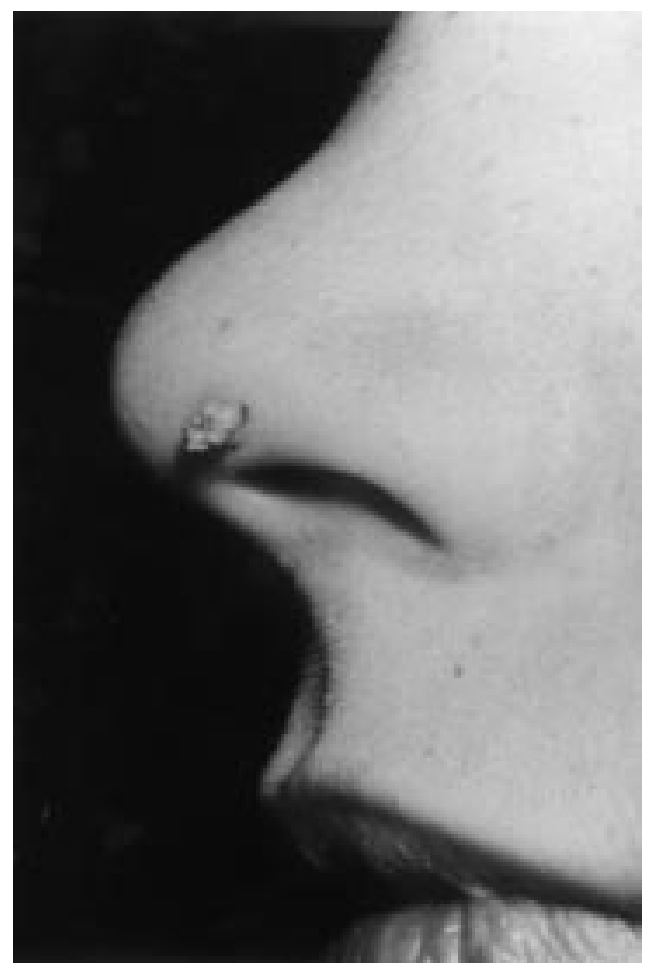

Figure 4 Digitate wart over nose. 


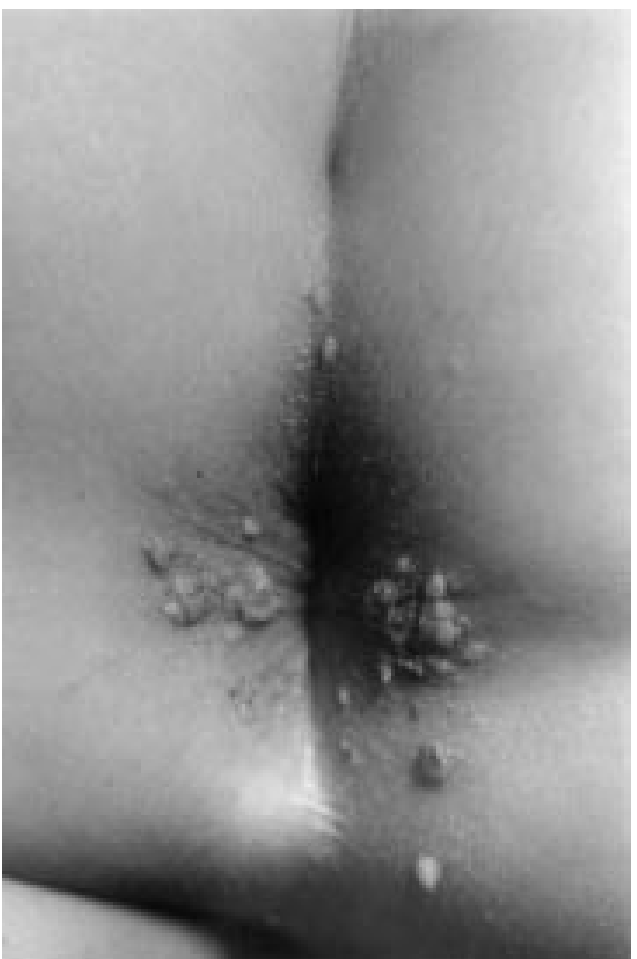

Figure 5 Perianal warts.

children for this unlicensed use. I have not had reason to use laser treatment for warts in children.

I have in the past "bought" warts with sweets or coins and encouraged the children "to pray to the Almighty in their night prayers for their warts to disappear" and supplied them with coloured postcards containing the appropriate message to hang on their bedroom walls/ ceilings, but this has not proved successful. I also doubt whether there is a place in foot wart management for the wart-biter cricket which is apparently alive and well in Great Britain.

\section{Conclusion}

Reassurance, patience, and regular paring of hard skin overlying plantar warts (if uncomfortable on walking) must be the key words in management of viral warts in children: because of this, and the ever increasing number of patient referrals often for more serious skin conditions, we do not give routine outpatient appointments to children with viral warts unless lesions are painful, over the face, or affect the genital area, or the family doctor has unsuccessfully tried the various measures mentioned above.

1 Reed BR. Warts (human papilloma virus infections). In: Fitzpatrick JE, Aeling JL, eds. Dermatology secrets. Philadelphia: Hanley \& Belfus Inc, 1996.

2 Kilkenny M, Merlin K, Young R, Marks R. The prevalence of common skin conditions in Australian school students: 1. Common, plane and plantar viral warts. $\mathrm{Br} \mathcal{F}$ Dermatol 1998;138:840-5.

3 Douglass MC, Koblenzer PJ, Moroz B, et al. Management of warts in children. Pediatr Dermatol 1987;4:36-54.

4 Gupta AK, Koren G, Shear NH. A double-blind, randomized, placebo-controlled trial of eutectic lidocaine/ prilocaine cream 5\% (EMLA) for analgesia prior to prilocaine cream $5 \%$ (EMLA) for analgesia prior to
cryotherapy of warts in children and adults. Pediatr Dermatol 1998;15:129-33.

5 Tackling warts on the hands and feet. Drug and Therapeutics Bulletin 1998;36:22-4. 